\title{
Discourse and Reflection Competencies Developed by Student Teachers through Repeated Children's Book Read Alouds: A Multiple Case Study
}

\author{
Clodie Tal \\ Department of Early Education, Levinsky College of Education, P.O. Box 48130, Tel Aviv 61481, Israel \\ Correspondence should be addressed to Clodie Tal, clodietal@gmail.com \\ Received 13 December 2011; Accepted 11 January 2012 \\ Academic Editors: İ. Dokme and D. Whitelock \\ Copyright ( $\odot 2012$ Clodie Tal. This is an open access article distributed under the Creative Commons Attribution License, which \\ permits unrestricted use, distribution, and reproduction in any medium, provided the original work is properly cited.

\begin{abstract}
This paper describes the development of discourse and reflection competencies by three early-age student teachers through repeated children's book reading (RCBR) in small, heterogeneous groups. The students were enrolled in a four-track, early-education preparation program at Levinsky College of Education in Israel. Research based on a multiple-case-study methodology, focused on an analysis of the students' interpretation of and reflections on the transcripts of the discourse throughout the three years of their fieldwork. Findings indicate that, over the three years, all three students relaxed their control of the discourse, allowing for more continuous literary discourse among the children. Differences in the developmental trajectories of the three students were manifested in the extent to which literary understanding and distinctive interpretations by the children were emphasized. Over the three years, all three students also developed a genuine concern for the children's well-being and participation in the group. Analysis of the students' protocols yielded a tentative formulation of milestones in the development of discourse and reflection competencies through teaching preparation studies.
\end{abstract}

\section{Introduction}

In spite of the common-sense logic of repeated, dialogic, children's book readings and the extensive body of data pointing to its benefit to children (e.g., [1-5]), such readings are rare in Israeli kindergartens and preschools. Although Israeli children are frequently exposed to picture books and other children's literature in kindergartens and preschools and stories are occasionally read aloud in plenary sessions, efforts are seldom made to systematically and thoroughly engage small groups of young children in discourse about the meanings attributed to the content and illustrations of these books. A teacher-led, heterogeneous, small-group, learning format was chosen based on a social-cultural approach [6] that emphasizes both the social nature of knowledge construction and the importance of discourse-oral language as a "carrier" of thought. Heterogeneous groups provide an opportunity to encourage children to deepen relationships, learn more about their peers in a safe, teacher-led context, and learn from—and teach—-their peers.
Repeated children's book reading (RCBR) was chosen as a core activity as it has the potential to enrich the "whole child" (e.g., $[1,5,7,8]$ ) and, when applied authentically, young children love it. "Illustrated books are not only the type of literature most commonly encountered by young children, but they offer a highly sophisticated, visual aesthetic experience, making high quality art present in tangible everyday activities" [1, page 13].

We adhere to Wells's claim [9, page 247] that "...both in childhood and in adulthood, most learning occurs in naturally-occurring, task-related apprenticeships, in which with guidance and social and emotional feedback, novices appropriate the values as well as the knowledgeable skills that enable them to persevere and achieve success." We regard RCBR as one such naturally occurring, authentic task.

\section{Goals of Repeated Children's Book Reading}

Young children have the potential to extract meaning from participating in RCBR. Moreover, they identify with book 
ideas, and heroes and have an opportunity to ponder their own life experiences. Sipe [1] suggests that the encounter with illustrated books evokes the following "impulses" or dispositions in young children:

(i) the hermeneutic impulse-to grasp the meaning of the narrative, either from the standpoint of within or without the text [1, page 189];

(ii) the personalizing impulse- - to forge links between the concepts, assumptions, narrative trajectories, and thematic meanings evoked or invited by the text and the reader's own psychic world [1, page 190];

(iii) the aesthetic impulse- to genuinely enjoy aesthetic aspects of the book and to artistically express feelings and thoughts evoked by the text [1, page 191].

Therefore, our goals for RCBR are to enhance the children's literary understanding and encourage them to share and discuss with peers and teachers their interpretations of the content and illustrations. Literary understanding is "a matter of engaging in literary meaning-making, of passionately interpreting stories with increasing sophistication, cognitive power, and delight" [1, page 3$]$. It follows that the adult who guides the read alouds has to create conditions that allow for expression of the child's disposition and coconstruction of the child's and small group's knowledge about the book and how it might be related to his or her real life.

\section{The Importance of the Discourse}

We must keep in mind that read alouds of children's books are not magic. As put by Meyer et al. [10], reading stories aloud does not always lead to the enhancement of children's literary understanding. The quality of the interaction with and among the children throughout the reading event determines the extent of interest in books and literary understanding in children. Indeed, Whitehurst [11] proposes that we engage children in dialogic reading in which "...the adult helps the child become the teller of the story. Children learn most from books when they are actively involved." Discourse in groups involves several active persons, however, and therefore the construction of literary understanding in a group rests on each participant's willingness to listen to the others and ponder their interpretations.

\section{Characteristics of Discourse Based on Vygotsky's Theory}

Dialogic reading can be regarded as the pedagogical implementation of Vygotskian sociocultural learning theory. Thus, both our preparation of student teachers and the lenses through which we interpret their texts (transcripts and reflections) are grounded in Vygotsky's [6] emphasis on the social nature of knowledge construction. Mediation is perceived as social guidance by an adult and/or more competent peer and regarded as a potent mechanism for development and learning when expressed in the interaction or discourse of the small group. "Knowledge building, whether conducted alone or in the company of others, is thus always situated in a discourse in which each individual contribution both responds to what has preceded and anticipates a further response" [12, page 16]. This principle of "responsivity" is one of the defining characteristics of the dialogue of knowledge building, the mode of discourse in which a structure of meaning is built up collaboratively over successive turns [12]. Bereiter [13] states that 'trust in students' and children's ability to take an active role in their own learning is obviously an essential prerequisite for the introduction of collaborative knowledge building. But for it to be worthwhile, the discourse must involve more than simply sharing of opinions. It must also result in progress in the sense of that sharing, questioning and revisiting of opinions leads to a new understanding that everyone involved agrees is superior to their own previous understandings" [13, page 6]. Bereiter and Scardamalia [14] emphasize ever-improvable understanding, the improvement of ideas as the goal of the discourse. We refer in this paper to allowing for children's ingenious ideas to be developed and discussed by the group.

To sum up, dialogic discourse focused on RCBR must therefore be characterized by an active inquiry into the text, illustrations, and relations between them by participants who listen to the other participants, to themselves, to their inner voices, and to the overt and concealed meanings of the text. In examining the students' protocols, we will look for responsivity to other participants and examine the extent to which the discourse focused on children's books contributed to the participants' literary understanding and to a continuous refinement of ingenious ideas raised by the children and agreed upon by the group.

As knowledge construction that occurs in sociocultural contexts ends up being uniquely incorporated into the participating individual's mind, to understand and assess professional development, we need to examine both discourse transcripts and reflections by the student teachers. Hence, this study addresses the following question. How did the student teachers' quality of discourse and reflection about the RCBR undergo change throughout the preparation years?

\section{Method}

To learn about the development of discourse and reflection competencies in student teachers, we examined three cases including the transcripts of read alouds and their reflections upon them during each of the three years of studies in which they engaged in RCBR. Thus, the research reported in this paper is based on a multiple-case-study methodology, as case studies often contain a substantial element of narrative. Good narratives typically approach the complexities and contradictions of real life [15, page 222]. Although the students were initially guided in their transcription of the discourses and in later writing their reflections based on their inspection of the transcripts, by the third year, all three had documentation that included narratives combining reflections with segments of discourses. Furthermore, although, in this study, we asked for at least one transcript and one reflection from each year of study, students handed in records containing summaries of partial or full reading cycles. 
5.1. Participants. Three 23- to 25-year-old, female student teachers at the end of their third year of studies participated in this research. The students were enrolled in an academic four-track, early education preparation program at Levinsky College of Education in Israel. The third year constitutes the last year of fieldwork at Levinsky College, as students are allowed to do an internship in public preschools and kindergartens in their fourth year of studies. Two of the students participating in the study were recruited in November 2010 based on the author's evaluation of their readings that they were typical students in good standing. The third student was chosen because her last read aloud, which she presented to an audience of students and staff at a conference in which all third-year education students discussed significant learning processes from their fieldwork, can be regarded as a prototype of dialogic discourse [15]. When approached by the author at the end of the academic year (in June 2011), it turned out that this student had not kept a copy of the documentation of her first-year readings. Nevertheless, the decision to include her in the study was based on the exemplary transcript she presented as well as the documented improvement of her discourse through the third study year. The other participants were 3-6-year-old children who participated in the read alouds of these students.

5.2. Preparation of the Student Teachers. The preparation of the student teachers to engage in RCBR in small, heterogeneous groups was guided by a progressive pedagogical approach drawn from Dewey's theory [16] and based on the belief that students learn best from repeated experiences that are reflected upon: "only by extracting the full meaning of each present experience are we prepared for doing the same thing in the future" [16, page 49$]$.

To establish small group RCBR as a routine in preschools, we believe that education students first have to experience it on a regular basis in their professional preparation. Therefore, all Levinsky, student teachers perform repeated illustrated-book reading in all their fieldwork placements from the very first semester of the first year. Furthermore, students are instructed to document the read alouds and then examine the transcripts or listen to audio- or video-taped discourses, to record at least one reflection on each read aloud and to set a plan for the next reading session based on the reflection and their conclusions.

5.3. Interpreting the Data. Our approach to interpreting the data is holistic rather than global or analytic. By this, we mean that we examine how the discourse evolves in each session (reading event) and how it develops from event to event and ask ourselves what seems to have been learned by the children and the student, what seems to have hindered discourse, and how the setup of the reading session was transformed by the student following reflection.

Reflections were examined for their acknowledgement of responsivity, understanding, and ingenuity in group interactions and for their ability to pinpoint both learning-building and learning-hindering segments of the discourse. The ultimate criterion was the student teacher's ability to act on the reflection and alter practice accordingly.

\section{Main Findings and Discussion}

6.1. Case 1-Ilana: Commitment to the Children's Well-Being and Participation. In her first year of studies, Ilana read $A$ Story of Five Balloons by Miriam Roth to a group of 3-4-year olds. In this book, Ruthie's mother buys colored balloons for Ruthie and her four friends. One by one, the balloons burst as the children play with them, until the final balloon floats off. "Bye-bye, red balloon..." say the children as they watch it fade away.

Ilana began the fourth reading of this book (on 14 January 2009) by asking the children if they remembered it. She pointed to the balloons and asked the children about the color of each. All the children answered "yes" or nodded, so Ilana started the reading. She initiated most of the questions and the children joined in, completing sentences that she read. From the children's participation, they seem to have remembered the words of the book. The questions Ilana asked were related to the colors of the balloons, and no attempt was made to discuss the children's feelings about the loss of the balloons. Moreover, at the end of the session, Ilana arbitrarily invited the children to draw the purple balloon and brought only purple colors. After coloring the balloons, she reread the book. Children emphasized the colors of the balloons in this discussion but did not initiate comments or questions.

On the one hand, the children seemed attentive and remembered the text. All the children participated, in keeping with Ilana's rules, and she paid attention to individual children. On the other hand, Ilana controlled the discoursewhat was to be discussed, the concepts to be clarified. Ilana's reflection reveals her tacit criteria for assessing the read aloud:

I enjoyed the activity; children listened to me. At first I was afraid to read the same story again and again, afraid that the children would be bored. I was positively surprised to discover that I can engage a group of children for a quarter of an hour while they listen. They are attentive, enjoy, and participate. I found that repeated book reading, in spite of my apprehension, does interest the children [January 2009, emphasis added].

Ilana's reflection indicates her criteria for assessing the quality of the discourse - the children's participation and enjoyment; their willingness to listen to her was key. No concern was expressed about understanding ideas related to the story.

At the beginning of the second year, Ilana reread The Magic Hat by Lea Goldberg to a group of children. During this second read aloud, unlike her first-year reading of $A$ Story of Five Balloons, Ilana sometimes allowed the discussion to unfold related to the children's wishes from the magic hat. In the segment that follows, the children explore the meaning of the girl's wish to be the biggest person in the world.

(35) Ilana [reading]: "And mother at night will not tell her to go to bed."

(36) Shirel: What a little mother she has [looking at the picture]. 
(37) Ilana: What a little mother! What's strange in this picture?

(38) Shirel: That she's little and she's big.

(39) Ohr: She's big and her mother is little.

(40) Ohr: She says: Go to bed! But the bed is small and she'll break the bed.

(41) Shirel: She'll break the chair! See that the chair is going to break. Her butt is big and the chair is little [smiles and opens her hands].

(42) Ohr: And she reaches the lamp.

(43) [Miriam joins the group and sits down.]

(44) Elian: If she wants to go to school, how will she go through the door? She's so big!

(45) Jonathan: If she's little?

(46) Ohr: Then she'll be able to get in.

(47) Jonathan [smiles]: She can get in.

(48) Ohr: Maybe if she's big she can't go into the room. She can't do a thing when she's big.

(49) Shirel: She can bend.

(50) Elian: She can't get out the door if she's big.

(51) Ilana resumes reading. [4 November 2009].

In lines 36 to 50, we witness a thorough exploration by the children of what happens to the girl when her wish to become the biggest person in the world is fulfilled. The children are allowed to explore the illustration and discuss this possibility among themselves. The book has a strong emotional appeal to the children, and at times they touch the boundary between the real and the imaginary.

Nevertheless, Ilana occasionally resumed control of the discourse (as seen, e.g., in line 103 below), which seemed to interfere as the children were vividly involved in discussing the content and meaning of the book with their peers.

(100) Ohr: I loved the story, all of it. I liked what she did with the magic hat.

(101) Ohr: I'd really like to have a magic hat like that because I'd like to ask for things for preschool, for my home, and for my brother and me.

(102) Shirel turns to Ohr: Would you like your magic to turn into a car?

(103) Ilana: Let's keep for later your requests for discussion when we'll all share our wishes.

Ilana's reflection on the November 4 read aloud was written a month later and reflects her understanding of the futility of some of her interventions.

After reading the book, when discussing the wishes, I felt that the topic was close to them, that they were keenly interested. After Ohr said he wanted a hat to help him fulfill his wishes and later on drew them, and also Elian showed an interest in making wishes and Shirel started another line of discussion about wishes three times, I think I should have allowed discussion about the children's wishes instead of continuing to read the book.

Also of importance is Ilana's genuine concern for the emotional well-being of all the children in the group, as also reflected in her October 30 reading in which she gently encouraged Miriam, a quiet and isolated girl, to participate in the discourse.

(25) Ilana: What did the girl ask for from the magic hat?

(26) Shirel: Hat, hat give me miracles.

(27) Ilana turns to Miriam: What did the girl ask for from the magic hat?

(28) Miriam whispers: A ship.

(29) Ilana: A ship. Right. Miriam says that the girl asked for a ship from the magic hat.

(30) Ohr: She said "Hat, hat make me big."

(31) Ilana: She asked to be big... So what does it mean that she asked for a ship and asked to be big? What are all these requests?

(32) Ohr: I don't know.

Shirel: Could you read it to us again? [10 October 2009].

In the segment above, we see that Ilana invited Miriam to be part of the group discourse. Miriam whispered her answer (the girl wishes the hat to become a ship_-line 28), and Ilana amplified this answer by recalling it twice in her summaries (in lines 29 and 31).

Toward the end of her second year of studies, Ilana's reflections show a transformation in how she approaches the discourse with the children and the read alouds. In June 2010, a year and a half after the first reflection, Ilana writes in response to a questionnaire about the meaning of RCBR.

At the beginning I would provide answers to the children, "control" the reading and the activity that followed. I planned the reading session carefully, all the details, and never deviated, even for a moment, from my plan. As time passed, I understood that the best way to assure the children's (and my own!) learning is to listen to the children, to use their knowledge to develop new learning, not to overlook children's statements that were not part of my planning, to be more flexible and open to change. Also, I no longer provide answers, but rather emphasize thinking tools, tools that help the children arrive at answers by themselves" [June 2010, emphasis in the original].

Thus, Ilana seemed to have reformulated her theory of how children learn, particularly with regard to participating in read alouds. As opposed to aspiring that the children listen to her, Ilana now states that "the best way to assure 
the children's (and my own!) learning is to listen to the children, to use their knowledge to develop new learning. ..." She positions herself as a learner as well as a teacher and understands that listening to the children also provides a way to plan how to continue the discourse. The transformation undergone by Ilana was gradual and the product of experiencing and reflecting upon more read alouds.

Of interest is Ilana's way of starting the read aloud by placing the book on the floor and inviting the children to explore it. Thus, at the beginning of the third year, Ilana eased her control and dared start the reading cycle by allowing the free exploration of the book and genuinely following the children's lead. One of the children, Ofek, pointed to the title and asked what was written there. Ilana asked the children what they thought it said. The children said it was the name of the book and started to discuss the meaning of the two figures (a girl and a preschool teacher) who appear on the cover. She then read to them the title of the book, Tell Me Your Name, and asked them to hypothesize what the book would be about. Ofek insisted that Ilana tell the group what was written under the title. As she had the impression that all the children were interested, Ilana talked with them about the author and the illustrator. As the discussion took some time, she left out the planned question-to hypothesize about the content of the book-and started to read it. At the end of the first reading session, she showed the children the first and last illustrations in the book. In the first, the girl seems embarrassed, afraid, ill at ease; in the last, she looks cheerful. Ilana asked the children to comment on the girl's feelings and what might have been the reason for her different emotional states at these two points in time. This approach of encouraging children to talk about feelings represented in the book is much more sophisticated than her tendency to directly ask the children how the heroes of the books and they themselves felt-as reflected in her discourse about The Magic Hat in her second year. In response to her question, Karin, one of the children, shared her experiences in a day care center. The other children did not seem to be interested in her story, and Ilana writes that she pondered what to do (reflection in action). She finished the session, left the book on the floor of the library for the children's possible further exploration, and suggested that Karin continues to tell her about her experience. Following this, Ilana wrote "one way to improve this in the future is to try to involve the children in the discussion about a child's story and not leave it as a discussion between the child and myself."

To sum up, Ilana seems to have developed an engaging way of reading books to children. She ensures that all the children have a chance to participate and adapts her reactions to the needs of individuals. The discourse she leads with the children has become continuous, and, at the beginning of the third year, Ilana seems to have no problem allowing the children to lead the discussion about the content. Ilana also insists that all children be familiar with the text and able to tell the story. In her reflections, however, Ilana does not mention any ideas raised by the children about the content of the story. This is not to say that the children did not leave the read alouds sessions without such insights. However, Ilana did not seem to be oriented toward enabling the children to reach an improved literary understanding. Nevertheless, she makes it possible for children to express their views in a pleasant and safe atmosphere.

6.2. Case 2-Naomi: Commitment to Achieving Understanding. In her first year, Naomi expects the children to participate in the reading, but she conducts a discontinuous discourse, primarily due to her attempt to direct it using preset questions. The following segment shows how the apparent commitment to preset questions hinders the children's construction of literary interpretations of the text. The segment presented below is from Naomi's sixth reading of Father Is Embarrassing by Meir Shalev to a group of 3-4-year olds. In this book, we are told about Efraim's father who does things in a way that does not suit the Western image of how dads behave. The father is a storyteller who takes care of the boy, while the mother, a media executive appearing on TV, is busy at work. Dad is a cheerful and eccentric pal who is not ashamed of showing affection for his son in public or, on the other hand, showing fear while watching a movie.

(43) Naomi [unrelated to what the children have been discussing]: Do you remember the subject of the book?

(44) Roy: That father does embarrassing things. I'll show you a picture.

(45) Naomi: What does embarrassing mean? Can you remember a situation when your mom or dad embarrassed you?

(46) All children: No!!!

(47) Naomi: So what's embarrassment?

(48) Tal: That you go wild a little bit [gives examples of embarrassing actions by children].

(49) Ophir: On a birthday when a child ruins a game.

(50) Roy: And he gets punished.

(51) Ophir: And he bumps into a table and treats fall on the floor.

(52) Roy [assertive]: I wanted to show something!

(53) Naomi: Yes, what did you want to show?

(54) Roy [browses through the book and stops at a page]: You can see here he's [the father] afraid during the show-that's embarrassing.

(55) Tal: It's not a show, it's a movie!

(56) Roy: You're right.

(57) Naomi: I'd like to ask you one last thing—which illustration do you like best? [26 May 2011].

Although Naomi's first question (line 43) was untimely, it had the effect of engaging the children in thinking about the main ideas of the book. Indeed, Roy volunteered to formulate this idea and bring evidence from the text (line 44). Instead of following through with Roy's initiative, however, Naomi picked from his answer the feature that apparently reminded her of her predetermined plan to ask children about the meaning of the word "embarrassment," seeking to connect the story to the children's lives. The children seemed to 
respond to her initiative, answering her questions, and, after a while Roy, seemingly an assertive boy, drew the attention of Naomi and the group (in line 52) to his desire to show something when Naomi launched her question. Naomi locally responds to Roy's initiative, and he indeed shows a very nice example of how the father embarrasses Efraim and for a short while manages to engage the other children in a discussion about his idea. Naomi, however, goes on to her next preplanned question, which illustration they liked best, without attempting to amplify or summarize the ideas brought up by Roy and related to her own initial question. Furthermore, this last question (line 57), asked towards the end of the repeated (sixth) reading cycle, invites children to go back to the particular (a preferred illustration) rather than continuing to deal with features of the book related to the special father-a discussion she interrupted.

Naomi's reflection following this reading indicates that she appreciates children's participation and collaboration with one another. "Children were attentive to their peers. I paid attention to the discourse and collaboration among the children, which led to a better understanding of the ideas." She did not, however, bring evidence of how the collaboration brought about a better understanding of ideas. Although she was aware that at the end of the session, “... I felt that I hurried and did not allow the children to express themselves. I did not respond enough to what the children had to say," Naomi does not elaborate upon this insight or relate to the content of the story, suggesting an alternative way to deal with the situation.

During the second year, Naomi seemed to lead continuous discourse throughout the repeated readings of the book One Dark Night by Ora Eyal. At the beginning of the fifth reading of the book, Naomi opens with:

(1) Naomi: Who remembers the name of the book we read? Daniel: Hannah.

(2) Eitan: Hannah Banana.

(3) Ron: That's not right.

(4) Lilach: One Dark Night.

(5) Naomi: Very nice. Daniel and Eitan, Hannah Banana is the main character in the story. Do you remember who wrote and illustrated the book? [2 December 2009].

This segment shows that Naomi listened and organized the discourse nicely among the children. Her intervention was timely, and the children's discourse led to mention of the book's title (line 4). Her organizing clarification at the end of the segment (line 5) was important, as it clarified the needed distinction between the title and the main figures in the story.

Furthermore, Naomi showed determination to enhance the children's feelings of competence by offering scaffolds that enabled them to believe in their ability to tell the story based on an examination of the illustrations. Naomi planned to have the children read the story, as she had the impression that all the children were familiar with it. The children, however, hesitated.
Daniel: But we don't know to how to say the writing.

Naomi: That's right, you don't know to read what's written, but you can look at the illustrations and tell the story that way.

Zohar: I know how to tell Little Red Riding Hood.

Naomi: Right-if you look at the pictures, you can tell the story. Who wants to start?

Daniel: Me. [2 December 2009].

The above segment is an interesting example of how Naomi enhances the feelings of competence of the children and scaffolds their attempts to tell the story, and this is just one example of her efforts to encourage the children to believe in their ability to read the story. Her reflections convey her understanding of the need to support the children emotionally as the basis of their participation in book reading. She mentioned, for example, that the two children who eventually told parts of the story did so when "I supplied them with a sense of security." She did not, however, elaborate at the end of her second year on ways to discuss the main ideas of the book with the children-the fear of night and darkness and the imaginary figures in it.

The third year of RCBR seemed to be especially meaningful for Naomi as during this year she developed a deep commitment to encouraging children to deal with ideas raised by the books and deepen their literary understanding. At the beginning of the third year, she began reading a book that appeared to be challenging for the 4-year olds- $A$ Little Crocodile with a Big Heart by Daniela Kolut. This book shows how complicated love can be between very different creatures - a short crocodile and a tall giraffe. She started reading, children asked questions, but she tended not to elaborate and continued reading aloud. The children listened. At the end of the first reading (27 October 2010), she again asked a preplanned question, "what did you like in the book?" Children had nothing to say in response. At this point, her reflection was deep and thorough. She was conscious that children may not have understood the plot and was critical of her own tendency to go on reading without having clarified issues and questions raised by the children. "The questions [I asked] at the end were arbitrary because the children did not understand the plot and I directed their answers to what they liked and didn't like..."

Therefore, in starting the second reading, Naomi noted that her main aim was to have the children, through discourse, understand the plot. In the subsequent sessions, she built dialogic discourse with the children. Questions and explanations alternated-sometimes offered by the children and sometimes by her. Sometimes she used experiential learning to clarify meanings. For example, she showed how a short person cannot notice the smile of a much taller person by pretending that she was the giraffe and asking for a child volunteer to be the crocodile, thereby showing the children that the volunteer crocodile was unable to see the giraffe's smile. Naomi also emphasized meanings in the discourse with the children. For example, when children said that going to the hospital was funny, she invited them to ponder whether getting hurt and needing hospitalization was really 
funny. She went on exploring main ideas with the children such as the impact on their feelings of differences between people and possible meanings of being stubborn (touching on nuances of determination versus inflexibility) in light of the remarkable perseverance of the crocodile to convince the giraffe of his sincere love for her. Furthermore, Naomi observed that the children explored the book and paid attention to details not mentioned in the text. Her notes after the fifth reading of the book (17 November 2010):

I put the book on the table, and before I could say a thing, Guy said, "In the story there are three animals in a hospital." And Tal added, "That's right they were hurt just like the crocodile." I was quite surprised as Guy and Tal discussed details of the story without me asking them. The interesting thing was that they paid attention to details in illustrations that are not mentioned in the verbal text. The story doesn't say anything other than the crocodile being hurt [probably the desire to illustrate a hospital explains the additional animals]. I then understood that the children explore the illustrations and are interested in this inquiry.

To sum up, this reflection could be seen as evidence of Naomi's emerging understanding of the children's ability to offer ingenious interpretations of texts as they become familiar with them through repeated reading and inquiry. She was aware of the difference between dialogic and skewed discourse. She was excited to discover that through discourse, guided but not controlled by her, the children both understood and enjoyed the book. Throughout her fieldwork years, Naomi developed her ability to scaffold the children's attempts to make sense of children's books and she became determined to enhance their belief in their ability to read books.

6.3. Case 3-Anna: Fostering Ingenious Interpretations of Literary Texts. In the third case, we show how a third-year student developed the ability to facilitate and encourage deep, ingenious interpretations of literary texts by children. As noted, Anna could not find the records of the readings from her first year of studies. Although we have records of the second year of her repeated children's books readings, we will deal in depth only with her third-year protocols as they show a transformation of the student's understanding of hers and the children's learning process from one reading session to the next.

Toward the end of her third year of studies and for the first time in her fieldwork, Anna discussed poems with the children rather than prose, from an illustrated poetry book. She chose to present poems focused on love as she had previously read A Little Crocodile with a Big Heart to the same group of children. The themes in these literary pieces were frustration and joy related to love.

The first poem Anna read with the children was "Hi Ho Hi Ha" by Shlomit Cohen Asif, which deals with love between a stallion and mare. Anna's thorough reflection on this poem following the discourse with a group of children (on 9 March
2011) was the basis for a meaningful transformation in her conceptualization of quality discourse with children:

Then I told the children that I brought them a poem and want to read it to them. I opened to the page and then Ido, a boy in my group, remarked, "There are no pictures." My answer was, "You're right, this is a book of poems." I think I was wrong here; first, I had to allow children to freely browse the book, to question him [Ido], and perhaps to reach their own conclusion that this was a book of poems and not a story book. Ido's question led to the possibility of inquiry [of the poem and book] and therefore, instead of continuing with my plan, I should have asked the children something like, "Let's try to think why the book has so few illustrations" and put the book on the floor near the children so they could freely inspect it. Instead, I was so eager to continue with my plan that I wasn't listening to the children...

I finished reading the poem, turned the book toward the children, and again they began to talk about the illustrated figures. Ido: "The boy is white and the girl is brown." Q: "Why do you think so?" Ido: "That he has a face like a dad and she like a mom." Gabriel: "No, because one is dark and the other's fair; the dark horse is the father and the fair horse is the mother." Maya: "I think so too." Gabriel: "The horse has a serious look so he's the boy." This tells me they were keenly interested in the topic and that I could have allowed them to discuss it. This was the first time it occurred to me that it is possible to continue the activity [discourse] following the children's lead and not following the order of my initial plan. I think that my adherence to the pre-set plan was not only because I was afraid the children could not cope with such a short text, but because I myself wondered if there was much to say about a poem [reflection following the 9 March 2011 reading; emphasis added].

We learn from Anna's reflection after the discourse with the children that she was able to pinpoint and analyze the factors that hindered development of a dialogic discourse that could yield understanding of a complicated text. She talks of her tendency to overly control the discourse and adhere to her plan, her doubts about the children's, and her ability to engage in a real discussion about a short text. The deep meanings conveyed by words, form of the text, and illustrations occurred to her only after examining her own records. Although preparation at Levinsky College encourages student teachers to engage in discourse that encourages young children's initiatives and improvement of ideas, we witness in Anna's reflection that "following the children's lead" as a pedagogical principle evolved in her mind in the wake of the reflections upon her own experience. It is interesting to note from Anna's insights that what interfered 
with the development of a dialogic discourse about a reading of the "Hi Ho Hi Ha" poem led to a real plan of changing the next poem reading with the children.

Indeed, three weeks later, Anna seems to apply her insight during the reading of another poem from the same book. This time, Anna placed the book on the floor in front of the children and allowed the children's free inspection of it. The children chose a poem that Anna initially thought would be too complicated for 4-year olds. Nevertheless, committed to her belief that she should follow the children's lead, as she previously stated, she proceeded to read "Ice Bear and Fire Bear" also written by Shlomit Cohen Asif. This poem is about two loving bears, an ice bear and a fire bear, who maintain their relationship by writing letters to each other and cope with a longing that is "difficult to banish." After many exchanges of letters, they eventually meet "at the end of the road" and "...hug a strong/Exciting hug." The meeting between the bears is observed by a little boy who closes the poem with the words, "Strange, I saw two bears/Kissing cheek and neck/And now I see nothing." The illustrations on one page show a brown and a white bear holding hands with an envelope seeming to fall beneath their hands and, on the facing page, a small boy seeming to watch the bears.

The following is a segment of the discourse that we consider a prototype of dialogic discourse that leads to the ingenious interpretations of literary texts by children.

(1) Gabriel: Today we learn this poem [points to the poem in the book].

(2) Anna: Wonderful, how well you remember.

(3) Anna: Do you remember the name of the first poem that we learned?

(4) Ophir: "Hi Ho and Hi Ha."

(5) Ophir: But we wanted that poem.

(6) Ophir: Fire Bear and Ice Bear [reads the poem's title from the book].

(7) Anna: Very beautiful.

(8) Anna: Who do you think is Ice Bear who is Fire Bear [pointing to illustrations]?

(9) All children: That's Ice Bear [pointing to the white bear illustration].

(10) All children: And Fire Bear [pointing to the brown bear illustration].

(11) Anna: Do you all agree that this is Fire Bear and this one is Ice Bear?

(12) All children: Yes.

(13) Gabriel: It's Fire Bear because it has several colors, brown, red, yellow and orange.

(14) Ophir: And that's Ice Bear because he has transparent color [is translucent].

(15) Anna: What other illustrations do you see?

(16) Ido: A child.

(17) Ophir: And letter.
(18) Ido: Maybe the boy found these bears?

(19) Gabriel: Bears want to be a statue, and the child goes to them and is afraid. Baaa.

(20) Anna: Could be. Now I'll read you the poem and see what the poem's all about.

(21) [Anna reading the poem.]

(22) Gabriel: We weren't right [says at the end of reading the poem].

(23) Ophir: That's all?

(24) Ophir: "Now I see nothing" [quoting the last sentence of the poem].

(25) Ophir: I didn't understand what he doesn't see.

(26) Ophir: What, doesn't he think they don't do anything?

(27) Gabriel: They're gone.

(28) [Following discussion among the children, I decided to re-read the last verse)] Anna: "A child was standing by the side and said: Strange, I saw two bears/Kissing cheek and neck/And now I see nothing."

(29) Ido: I know why they disappeared because the ice made him a statue, and it melted.

(30) Ophir: Because they kissed, and then they were too close to each other, and he was too hot, and he was too cold. He melted the ice, and ice put out the fire.

(31) Ido: They got mixed up and disappeared [transcript of reading from 30 March 2011].

The discourse among the children led to interesting interpretations that can be considered ingenious (lines 29-31). The process of meaning making was enabled by the children's keen interest in and examination of both verbal text and illustrations. Anna the student teacher consciously adopted the role of the interested audience as well as facilitator. At first, after allowing a keen observation of the text and free discussion among the children, Anna made sure that the children notice the illustration pointing to the main characters and features in the poem: the fire bear, the ice bear, the boy, and the letter (lines 8-17). She then decided, as she wrote in her reflection, to reread the last verse (line 28) after listening to the children and paying attention to Gabriel's conclusion (in line 27) that the bears disappeared. Anna wrote in her reflection that she was positively surprised by the children's ability to notice after only one reading that the bears disappeared; indeed, this is a remarkable insight because although the text suggests that the bears might have disappeared, the illustrations of the two bears remain on the page in front of the children. Anna stated that her intention was to encourage the children to raise hypotheses that would explain the disappearance of the bears. As the timing of her repetition of the last verse was exact and suited the discourse managed by the children, she did not have to ask any additional, direct questions. Mere repetition of the last verse: "A child was standing by the side and said: Strange, I saw two bears/Kissing cheek and neck/And now I see nothing" led to the children's genuine and ingenious interpretations 
(lines 29-31). This segment of discourse seems to fit Bereiter's [13] definition of progressive dialogic discourse as one that generates the agreed upon knowledge building. Gabriel, Ophir, and Ido contributed to the group's interpretation of this poem by listening to their peers while paying attention to features of the poem and offering their real questions and interpretations. Nevertheless, Anna noticed in her reflection that Daniel, a quiet girl, did not participate. As a result, Anna planned to make an effort in the next session to enable Daniel's participation. Indeed, having all the children participate has been an issue that Anna has been dealing with since her second year of studies. In that year, the children's discourse was often interrupted by Anna's attempt to convince a little girl with challenging behavior to participate.

To sum up, Anna developed by the third year of fieldwork both an understanding and the skill to encourage real dialogic discourse leading to the group's formulation of ingenious ideas related to literary texts and illustrations. Nevertheless, she still needs to improve her ability to include all children in the group discussions.

6.4. Summary of the Findings. The learning trajectories of the three student teachers share commonalities but also differ in some ways.

6.4.1. Commonalities. All three students started out by controlling the discourse with the children primarily through the use of rigid, predetermined questions and adhering to set plans; by their third year of fieldwork, they were able to become involved in the discourse, allowing for the free exploration of books by the children as well as questions and proposals initiated by them. Early discourses tended to be discontinuous due to the students' preset questions or poor management of the children's behavior, but these became continuous with the students' emergent ability to listen to the children and encourage discussions focused on the ideas, content, and illustrations of the books. Moreover, children participating in the discourse guided by all three students seemed to be able to tell the story/poem in its entirety, to reconstruct it, as called for by Tolchinsky [17]. All students showed concern for the participating children's emotional well-being. Assuring participation in the group discourse and their expression of thoughts and feelings is one of the primary means adopted by students to assure the children's well-being. Nevertheless, encouraging children to cope with challenges, to experience an authentic feeling of understanding, and to overcome difficulty could contribute to a positive self-perception as well [18]. Although the student teachers did not necessarily note in their reflections the relationship between efforts to understand and well-being, they developed sophisticated scaffolds to enable the children to understand and overcome difficulties.

6.4.2. Differences. Students differed in the extent to which they were able to ensure the participation of all the children. Anna, the student whose case was presented last, was aware of the lack of participation in the discourse of one of the children but does not manage to secure this girl's ongoing participation.
An examination of the students' reflections show that they differ regarding their conscious desire to enhance the children's literary understanding as a main goal of the RCBR. Anna seemed to emphasize literary understanding from the first existing record, Naomi developed a genuine interest in children's understanding in the third year and systematically acted on it, while Ilana overtly addresses the issue only partially in her second year, placing a greater emphasis on the children's participation and emotional well-being. And yet, Ilana engages in isolated steps that have the potential to enhance the children's literary understanding, such as inviting them to compare two contradictory illustrations. Not being part of a conscious plan, however, literary understanding was not systematically pursued by Ilana.

Nevertheless, Ilana's reading of The Magic Hat in her second year of studies and Naomi's reading of Father Is Embarrassing in her first year indicate that if the children are genuinely interested in the book and the student is caring and does not interfere with the literary discourse led by the children, the children do develop literary understanding about the books repeatedly read, even if he student does not necessarily acknowledge and appreciate the children's efforts. However, students can contribute to the children's literary understanding by consciously arranging a reading that facilitates the emergence of literary understanding as reflected in the case of Anna guided reading of the poem "Ice Bear and Fire Bear."

6.5. Milestones in the Development of Discourse and Reflection Competencies. Examination of the three student protocols led to the formulation of tentative milestones in the development of discourse and reflection competencies related to RCBR. In chronological order, these stages reflect:

(1) discourses controlled by a guiding adult that are characterized by discontinuity, which hinders learning and understanding;

(2) discourses in which the guiding adult is caring and encourages the participation of all the children, which may lead to literary understanding;

(3) discourses led by guiding adults who consciously and systematically aspire to enhance the children's literary understanding;

(4) discourses led by guiding adults who consciously and systematically encourage the children's unique literary interpretations.

All three students in our study started at level 1 and ascended to levels 2, 3, or 4. Not all students attained the fourth and highest level. Professional development seems to be facilitated by the repeated experience of guiding cycles of children's reading and reflecting on them. In the discussion below, we consider suggestions for improving student preparation that might enhance literary understanding and interpretation and offer ideas for future research. 


\section{Discussion}

In this paper, we showed that it is meaningful and important to look at both the student teachers' transcripts of discourse and their reflections in order to gain insight into the trajectories of their professional development. We should always keep in mind, however, that we have access only to partial evidence of the learning process related to discourse focused on literary understanding and its impact on the participants' lives. The evidence can never be complete as much of the transformational learning processes take place in the minds of the participants (children and students) during and after the read alouds. Nevertheless, it is important for teacher trainers and education researchers to be committed to as extensive documentation as possible of the participation (by children and students) and the insights in order to improve our understanding of the learning and social processes involved in literary discourses with young children.

This study shows that experience and reflection on the experience of RCBR are likely to contribute to the student's development of more dialogic discourse and more continuous discourse led by children. Our current preparation, however, does not necessarily foster a conscious effort in all students to enhance the children's literary understanding and unique interpretation of books. Therefore, we plan to introduce into our preparation program a group inquiry of children's books as mandatory preparation prior to their implementation of RCBR with children. Specifically, we will expect all our students to reach a deep understanding of the children's books to be read by participating in a group inquiry of these books in the company of their colleagues and guided by college mentors.

We also suggest to further refine and validate, in future research with larger samples of students, the definitions of milestones in the development of discourse and reflection competencies related to RCBR.

\section{References}

[1] L. R. Sipe, Storytime: Young Children's Literary Understanding in the Classroom, Teachers College of Columbia University, New York, NY, USA, 2008.

[2] G. J. Whitehurst, F. L. Falco, C. J. Lonigan et al., "Accelerating language development through picture book reading," Developmental Psychology, vol. 24, no. 4, pp. 552-559, 1988.

[3] I. L. Beck and M. G. McKeown, "Text talk: capturing the benefits of read-aloud experiences for young children," Reading Teacher, vol. 55, no. 1, pp. 10-20, 2001.

[4] B. Z. Keifer, The Potential of Picture Books: From Visual Literacy to Aesthetic Understandings, Prentice-Hall, Englewood Cliffs, NJ, USA, 1995.

[5] B. G. Doyle and W. Bramwell, "Promoting emergent literacy and social-emotional learning through dialogic reading," Reading Teacher, vol. 59, no. 6, pp. 554-564, 2006.

[6] L. Vygotsky, Mind in Society: The Development of Higher Psychological Processes, Harvard University Press, Cambridge, Mass, USA, 1978.

[7] N. Kucirkova, D. Messer, and D. Whitelock, "Sharing personalised books: a practical solution to the challenges posed by home book reading interventions," Literacy Information \& Computer Education Journal, vol. 1, no. 3, pp. 263-272, 2010.

[8] C. Tal, "One more time: repeated picture book reading-an ecological initiative," Hed Hagan, vol. 69, no. 2, pp. 4-22, 2004 (Hebrew).

[9] G. Wells, "Dialogue, inquiry, and the construction of learning communities," in Transforming Learning in Schools and Communities, B. Lingard, J. Nixon, and S. Ranson, Eds., pp. 236257, Continuum, London, UK, 2008.

[10] L. Meyer, J. Wardrop, S. Stahl, and R. Linn, "Effects of reading storybooks aloud to children," Journal of Educational Research, vol. 88, pp. 69-85, 1994.

[11] G. H. Whitehurst, "Dialogic Reading: An Effective Way to Read to Preschoolers," Institute of Education Sciences, U.S. Department of Education, 1992/2008, http://www.ldonline .org/article/Dialogic_Reading\%3A_An_Effective_Way_to_Read_ to_Preschoolers?theme=print.

[12] G. Wells, "Dialogic inquiry in education: Building on the legacy of Vygotsky," in Vygotskian Perspectives on Literacy Research: Constructing Meaning through Collaborative Inquiry, C. D. Lee and P. Smagorinsky, Eds., pp. 51-85, Cambridge University Press, New York, NY, USA, 2000.

[13] C. Bereiter, "Implication of post-modernism for science, or, science as progressive discourse," Educational Psychologist, vol. 29, no. 1, pp. 3-12, 1994.

[14] C. Bereiter and M. Scardamalia, "Rethinking learning," in The Handbook of Education and Human Development, D. R. Olson and N. Torrance, Eds., pp. 485-513, Blackwell, Cambridge, Mass, USA, 1996.

[15] B. Flyvbjerg, "Five misunderstandings about case-study research," Qualitative Inquiry, vol. 12, no. 2, pp. 219-245, 2006.

[16] J. Dewey, Experience and Education, Simon and Schuster, New York, NY, USA, 1938.

[17] L. Tolchinsky, The Cradle of Culture and What Children Know about Writing and Numbers before Being Taught, Developing Mind Series, Lawrence Erlbaum Associates, Mahwah, NJ, USA, 2003.

[18] A. Bandura, Social Foundation of Thought and Action: A Social Cognitive Theory, Prentice-Hall, Englewood Cliffs, NJ, USA, 1986. 

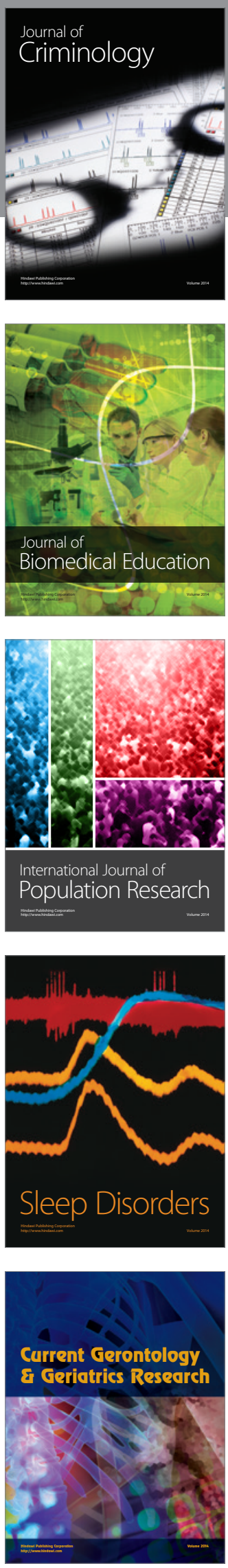
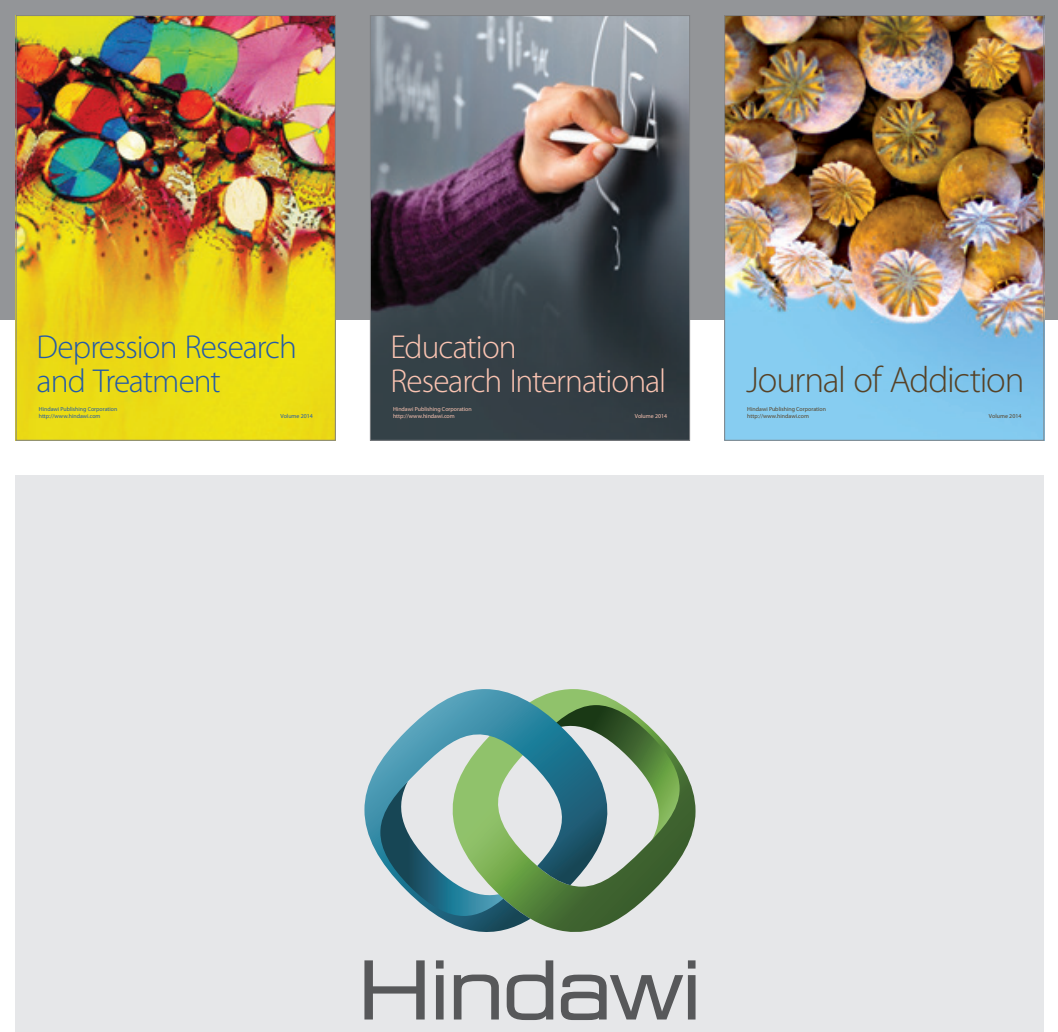

Submit your manuscripts at

http://www.hindawi.com

Child Development Research
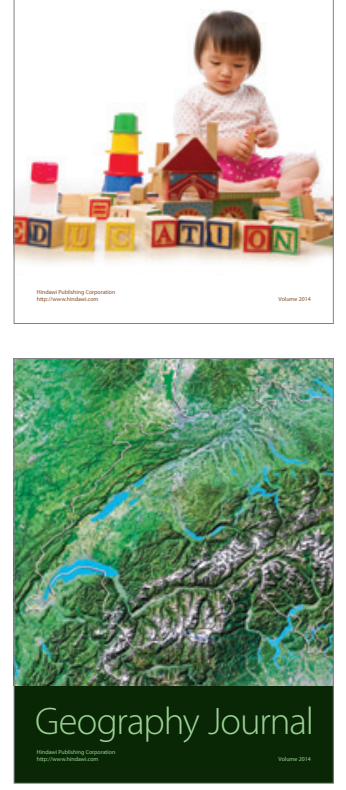

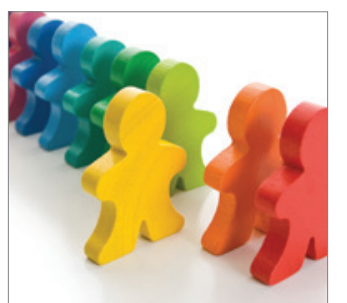

Autism

Research and Treatment
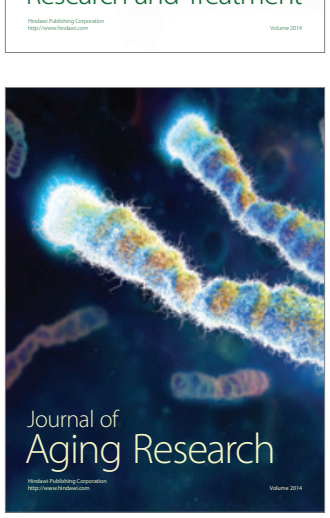
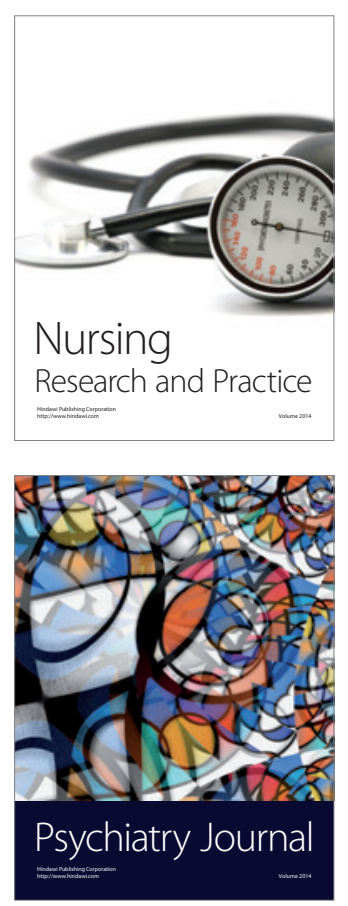
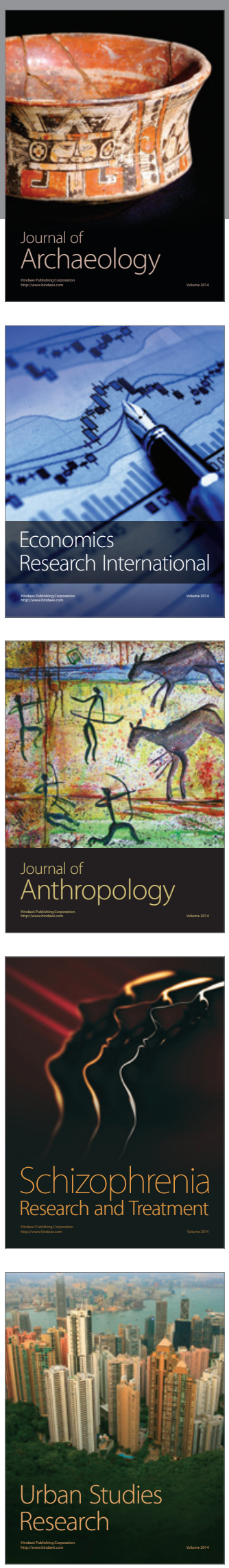